\title{
PRODUTIVIDADE DO FEIJOEIRO IRRIGADO DEVIDO A REGULADORES DE CRESCIMENTO E CULTURAS ANTECESSORAS DE COBERTURA ( $\left.{ }^{1}\right)$
}

\author{
TATIELY GOMES BERNARDES $\left({ }^{2}\right)$; PEDRO MARQUES DA SILVEIRA $\left({ }^{3 *}\right)$; \\ MARCOS ANTÔNIO MACHADO MESQUITA $\left({ }^{2}\right)$
}

\begin{abstract}
RESUMO
O objetivo deste trabalho foi avaliar os efeitos de regulador de crescimento aplicado na semente e foliar e de culturas de cobertura na produtividade do feijoeiro irrigado. O delineamento experimental foi em parcelas subdivididas, em blocos casualizados com quatro repetições. Nas parcelas constaram como culturas utilizadas como coberturas do solo, as leguminosas guandu-anão (Cajanus cajan L. Millsp); estilosantes (Stylosanthes guianensis Aublet Sw. var. vulgaris); crotalária (Crotalaria spectabilis Roth.), e as gramíneas milheto (Pennisetum glaucum L. R. Br.); sorgo granífero (Sorghum bicolor L. Moench); capim mombaça (Panicum maximum Jacq); braquiária (Brachiaria brizantha Hochst ex A. Rich. Stapf.); e braquiária em consórcio com milho (Zea mays L.). Nas subparcelas constaram os seguintes tratamentos: testemunha; $500 \mathrm{~mL}$ de regulador de crescimento (RC) em $100 \mathrm{~kg}$ de sementes; 250 $\mathrm{mL} \mathrm{ha}^{-1}$ de RC no estágio de desenvolvimento V4, tratamento foliar; e $500 \mathrm{~mL}$ de RC em $100 \mathrm{~kg}$ de sementes e $250 \mathrm{~mL} \mathrm{ha}^{-1}$ de RC com aplicação foliar, no estágio de desenvolvimento V4. Aos 84 dias após o corte das culturas de cobertura foi realizada a semeadura do feijoeiro, cultivar BRS Valente, sob pivô central. Foram avaliados o rendimento de grãos e os componentes de rendimento do feijoeiro. O rendimento do feijoeiro não foi positivamente influenciado pelos tratamentos, mas sim pelas culturas de cobertura.
\end{abstract}

Palavras-chave: Phaseolus vulgaris L., hormônios vegetais, cerrado, savana.

\section{ABSTRACT \\ PRODUCTIVITY OF IRRIGATED COMMON BEAN DUE TO GROWTH REGULATOR AND PREDECESSOR COVER CROPS}

The objective of this work was to evaluate the effects of growth regulator applied in the seed and to foliate and cover crops in the productivity of the irrigated common bean plant. The experimental design was a randomized block on split-plot, with four replications. The plots of the two experiments consisted of CROPS used as soil cover, as the leguminous: Cajanus cajan, Stylosanthes guianensis, Crotalaria spectabilis, and the grasses: Pennisetum glaucum, Sorghum bicolor, Panicum maximum, Brachiaria brizantha, and B. brizantha associated with Zea mays. The subplots consisted of the following treatments: control; $500 \mathrm{~mL}$ of growth regulator (RC) in $100 \mathrm{~kg}$ of seeds; $250 \mathrm{~mL}$ of RC per hectare in the V4 development stage, foliar treatment; and, $500 \mathrm{~mL} \mathrm{RC}$ in $100 \mathrm{~kg}$ of seeds and $250 \mathrm{~mL}$ of RC per hectare via foliar, in the V4 development stage. To the 84 days after the cut of the cover crops common bean cultivar BRS Valente was sown. They were evaluated the grain yield, and its components. The common bean grain yield did not significantly influenced the treatments with growth regulator applied via seeds and foliar. The common bean grain yield was positively influenced by predecessor cover crops.

Key words: Phaseolus vulgaris L., vegetable hormones, Cerrado, savanna.

$\left({ }^{1}\right)$ Parte da dissertação de mestrado da primeira autora, apresentada à Universidade Federal de Goiás (UFG). Recebido para publicação em 28 de julho de 2008 e aceito em 15 de setembro de 2009.

$\left({ }^{2}\right)$ Universidade Federal de Goiás, Escola de Agronomia e de Engenharia de alimentos, Campus Samambaia, Caixa Postal 131,74001-970 Goiânia (GO). E-mails: tatielygb@gmail.com; marcos.a.mesquita@hotmail.com

$\left({ }^{3}\right)$ Embrapa Arroz e Feijão, Caixa Postal 179, 75375-000 Santo Antônio de Goiás (GO). E-mail: pmarques@cnpaf.embrapa.br $\left({ }^{*}\right)$ Autor correspondente. 
O feijoeiro (Phaseolus vulgaris L.) destaca-se entre as principais culturas anuais em adaptação ao sistema plantio direto (SPD). A palhada das plantas de cobertura na superfície do solo é o principal componente de sucesso do SPD nos cerrados. WUTKE et al. (1998) avaliaram o efeito residual de culturas graníferas e adubos verdes na cultura do feijoeiro irrigado, e as produtividades médias obtidas foram de $1826 \mathrm{~kg} \mathrm{ha}^{-1}$, após o milho, e de $1672 \mathrm{~kg} \mathrm{ha}^{-1}$, em sucessão ao guandu. Em vários trabalhos, têm sido demonstrada variação das produtividades de grãos do feijoeiro em razão da cultura precedente, de 1300 $\mathrm{kg} \mathrm{ha}^{-1}$ a $2900 \mathrm{~kg} \mathrm{ha}^{-1}$ (Silveira et al., 2005; SILVA, 2006; Toledo-SouZA, 2006).

A aplicação de produtos em tratamento de sementes ou foliarmente tem se tornado uma prática agrícola rotineira. Segundo VieIRA (2001), com o uso de regulador de crescimento à base de ácido índolbutírico $0,005 \%$, cinetina $0,009 \%$ e ácido giberélico $0,005 \%$ nas culturas de feijão, arroz e milho resultou em efeito positivo e significativo nas variáveis relacionadas à produtividade, quando comparadas ao controle. A máxima produtividade de grãos por planta de feijoeiro foi de $35,9 \mathrm{~g}$, na concentração de $2,4 \mathrm{~mL}$ do regulador de crescimento, superior em $35,8 \%$ ao controle. Cовucci et al. (2005), em três experimentos desenvolvidos na região de Unaí (MG), detectaram aumento significativo na produtividade do feijoeiro, independentemente do cultivo utilizado, convencional ou plantio direto com aplicação de regulador de crescimento nas fases fisiológicas R5 e R7, pré-floração e formação de vagens, respectivamente, com produtividade média variável de 2148 a $3816 \mathrm{~kg} \mathrm{ha}^{-1}$ e de 1810 a $2951 \mathrm{~kg} \mathrm{ha}^{-1}$ nas testemunhas. CASTRO et al. (2005) obtiveram incremento na massa seca das raízes de feijoeiro, quando se utilizou regulador de crescimento até a concentração de $10 \mathrm{~mL} \mathrm{~kg}^{-1}$ de semente. Também, houve aumento no número de vagens por planta, no número de grãos por vagem e na massa seca de grãos por planta, na concentração de $5 \mathrm{~mL} \mathrm{~kg}^{-1}$ de semente.

Visando-se ao aumento da produtividade do feijoeiro irrigado, neste trabalho o objetivo foi avaliar os efeitos de regulador de crescimento aplicado na semente e foliarmente e de culturas de cobertura como: crotálaria, guandu, estilosantes, braquiária, mombaça, milheto, sorgo e braquiária em consórcio com milho.

O experimento foi instalado na Embrapa Arroz e Feijão, no município de Santo Antônio de Goiás, GO, cujas coordenadas geográficas são: latitude $16^{\circ} 28^{\prime} 00^{\prime \prime} \mathrm{S}$, longitude $49^{\circ} 17^{\prime} 00^{\prime \prime} \mathrm{W}$ e altitude de 823 metros. Segundo a classificação de Köppen, o clima é do tipo Aw, tropical de savana, megatérmico, com temperatura média anual do ar de $22,6{ }^{\circ} \mathrm{C}$, com médias mínimas e máximas de $14,1{ }^{\circ} \mathrm{C}$ e $31,3{ }^{\circ} \mathrm{C}$, respectivamente. A perda média anual por evaporação, medida em tanque classe "A", é da ordem de $1938 \mathrm{~mm}$ (Silva et al., 2004). O solo é classificado como Latossolo Vermelho distrófico, de textura argilosa (580 $\mathrm{g} \mathrm{kg}^{-1}$ de argila, $130 \mathrm{~g} \mathrm{~kg}^{-1}$ de silte e $290 \mathrm{~g} \mathrm{~kg}^{-1}$ de areia). Na camada do solo agricultável $(0-20 \mathrm{~cm})$, na análise química do solo, anterior à instalação do experimento, foram obtidos os seguintes resultados analíticos (Toledo-SouzA, 2006): $\mathrm{pH}\left(\mathrm{H}_{2} \mathrm{O}\right): 5,6$; $\mathrm{Ca}: 1,91 \mathrm{cmol}_{\mathrm{C}} \mathrm{dm}^{-3} ; \mathrm{K}: 0,31 \mathrm{cmol}_{\mathrm{c}}$ $\mathrm{dm}^{-3}$; P: $34 \mathrm{mg} \mathrm{dm}^{-3}$; e matéria orgânica: $21 \mathrm{~g} \mathrm{dm}^{-3}$.

O delineamento experimental foi o de blocos ao acaso com parcelas subdivididas e quatro repetições, em esquema fatorial $8 \times 4$. Nas parcelas os tratamentos consistiram de três leguminosas e cinco gramíneas, sendo estas, respectivamente: guandu [Cajanus cajan (L.) Millsp. cv. anão]; estilosantes (Stylosanthes guianensis Aublet Sw. var. vulgaris) cv. Campo Grande; crotalária espectábilis (Crotalaria spectabilis Roth.); milheto (Pennisetum glaucum L. R. Br.) cv. BN-2; sorgo granífero [Sorghum bicolor (L.) Moench] cv. BR 304; capim mombaça (Panicum maximum Jacq) cv. Mombaça; braquiária (Brachiaria brizantha Hochst ex A. Rich. Stapf.) cv. Marandú; e braquiária em consórcio com milho (Zea mays L.) híbrido BRS 3003. Nas subparcelas constaram os seguintes tratamentos: T1: testemunha (tratamento com água); T2: $500 \mathrm{~mL}$ de regulador de crescimento (RC) em $100 \mathrm{~kg}$ de sementes; T3: $250 \mathrm{~mL}$ de RC por hectare no estágio de desenvolvimento $\mathrm{V} 4$, ou seja, quando o feijoeiro está na fase vegetativa, com a terceira folha trifoliolada completamente expandida, tratamento foliar; e, T4: 500 $\mathrm{mL}$ RC em $100 \mathrm{~kg}$ de sementes e $250 \mathrm{~mL}$ de RC por hectare em aplicação foliar, no estágio de desenvolvimento V4. A dimensão de cada sub-parcela foi de $15 \mathrm{~m}^{2}$ (2,5 $\left.\mathrm{m} \times 6 \mathrm{~m}\right)$.

A semeadura das culturas de cobertura foi realizada mecanicamente em 18 de novembro de 2005, com $20 \mathrm{~kg} \mathrm{ha}^{-1}$ de sementes de braquiária, mombaça e de milho, $25 \mathrm{~kg} \mathrm{ha}^{-1}$ de sementes de guandu, $40 \mathrm{~kg} \mathrm{ha}^{-1}$ de sementes de milheto, $10 \mathrm{~kg} \mathrm{ha}^{-}$ ${ }^{1}$ de sementes de sorgo, $1,4 \mathrm{~kg} \mathrm{ha}^{-1}$ de sementes de estilosantes e $8 \mathrm{~kg} \mathrm{ha}^{-1}$ de sementes de crotalária. Os espaçamentos entre linhas foram de $0,4 \mathrm{~m}$ para as culturas de braquiária, milheto, mombaça e estilosantes e $0,8 \mathrm{~m}$ para as culturas de milho (consórcio com braquiária), guandu, crotalária e sorgo. A adubação de semeadura foi de $400 \mathrm{~kg} \mathrm{ha}^{-1}$, da fórmula 4-30-16, para todas as culturas. Realizouse adubação de cobertura no milho e no estilosantes, aos 50 dias após a semeadura, com $30 \mathrm{~kg}$ de $\mathrm{N}$, na forma de uréia. Aos quatro meses após a semeadura, as culturas de coberturas foram cortadas. 
As fases de corte foram: na maturação de grãos para milho, sorgo, milheto e guandu; na fase de florescimento para braquiária e capim mombaça; e, na fase vegetativa para estilosantes.

A semeadura do feijoeiro foi realizada em 23 de junho de 2006, utilizando a cultivar BRS Valente, pertencente ao grupo preto, arbustivo, de hábito de crescimento indeterminado (tipo II - com ramificações abertas). O espaçamento foi $0,5 \mathrm{~m}$ entre linhas, utilizandose 18 a 22 sementes por metro quadrado, e estas foram colocadas a aproximadamente $5 \mathrm{~cm}$ de profundidade. A adubação de semeadura foi realizada mecanicamente durante a abertura dos sulcos, utilizando-se $400 \mathrm{~kg} \mathrm{ha}^{-1}$ da fórmula 5-30-15. As sementes de feijão foram colocadas à mão nos sulcos abertos.

O regulador de crescimento utilizado foi à base de ácido índolbutírico (auxina) 0,005\%, cinetina (citocinina) 0,009\%, e ácido giberélico (giberelina) 0,005\%. Aplicou-se o produto diretamente sobre as sementes acondicionadas em sacos plásticos. A pulverização foliar foi realizada no final da tarde, quando não havia ventos fortes, com pulverizador costal manual.

Foram efetuadas duas adubações de cobertura com uréia aos 24 e 38 dias após emergência, aplicando-se 32 e $40 \mathrm{~kg} \mathrm{ha}^{-1}$ de $\mathrm{N}$, respectivamente. Aos 25 dias após a semeadura foram aplicados os herbicidas fomesafen $0,25 \mathrm{~kg} \mathrm{ha}^{-1}$ i.a. e fluazifop-pbutil $0,188 \mathrm{~kg} \mathrm{ha}^{-1}$ i.a., e o inseticida tiametoxam 0,025 $\mathrm{kg} \mathrm{ha}^{-1}$ i.a. O método de irrigação utilizado foi o de aspersão, sistema pivô central.

Foram avaliadas as seguintes variáveis: estandes inicial e final (número de plantas $\mathrm{m}^{-2}$ ), massa de 100 grãos (g), número de vagens por planta, número de grãos por vagem e rendimento de grãos $(\mathrm{kg}$ $\left.\mathrm{ha}^{-1}\right)$. As médias foram comparadas entre si, pelo teste de Tukey a $5 \%$ de probabilidade.

As variáveis analisadas no feijoeiro, estande inicial e final, massa de cem grãos, número de vagens por planta, número de grãos por vagem, e rendimento de grãos não foram positiva e significativamente influenciadas pelos tratamentos com o regulador de crescimento, assim como a interação do produto com as culturas de cobertura (Tabela 1). Resultado semelhante foi constatado por AlLEONI et al. (2000), utilizando regulador de crescimento (ácido índolbutírico $0,005 \%$, cinetina $0,009 \%$, e ácido giberélico $0,005 \%$ ) no tratamento de sementes e em aplicação foliar.

Tabela 1. Rendimento de grãos, estande inicial, estande final, número de vagem por planta, número de grãos por vagem e massa de cem grãos do feijoeiro cv. BRS Valente cultivado em sucessão à diferentes culturas de cobertura, e tratado com regulador de crescimento por tratamento de sementes (R.C.S.) e por aplicação foliar (R.C.F.). Santo Antônio de Goiás (GO), 2006

\begin{tabular}{|c|c|c|c|c|c|c|}
\hline Tratamento & Estande inicial & Estande final & $\begin{array}{l}\mathrm{N}^{\mathrm{o}} \text { vagem } \\
\text { por planta }\end{array}$ & $\begin{array}{l}\mathrm{N}^{\mathrm{o}} \text { de grãos } \\
\text { por vagem }\end{array}$ & $\begin{array}{l}\text { Massa de } \\
100 \text { grãos }\end{array}$ & Rendimento \\
\hline & \multicolumn{2}{|c|}{ plantas $\mathrm{m}^{-2}$} & & & $\mathrm{~g}$ & $\mathrm{~kg} \mathrm{ha}^{-1}$ \\
\hline Braquiária consorciada & 17,2 & 14,0 & $9,2 \mathrm{a}$ & $4,04 \mathrm{ab}$ & $19,2 \mathrm{a}$ & $1959 \mathrm{ab}$ \\
\hline Braquiária & 17,8 & 12,9 & $9,0 \mathrm{a}$ & $3,89 \mathrm{~b}$ & $18,7 \mathrm{a}$ & $1600 \mathrm{~b}$ \\
\hline Milheto & 16,6 & 15,0 & $10,3 \mathrm{a}$ & $4,31 \mathrm{ab}$ & $19,7 \mathrm{a}$ & $2485 \mathrm{a}$ \\
\hline Mombaça & 17,0 & 12,9 & $11,1 \mathrm{a}$ & $3,93 \mathrm{ab}$ & 20,7 a & $2120 \mathrm{ab}$ \\
\hline Sorgo & 16,7 & 15,1 & 10,0 a & $4,07 \mathrm{ab}$ & $18,8 \mathrm{a}$ & $1777 \mathrm{~b}$ \\
\hline Crotalária & 17,2 & 13,9 & 8,3 a & $4,27 \mathrm{ab}$ & $19,2 \mathrm{a}$ & $1696 \mathrm{~b}$ \\
\hline Estilosantes & 18,6 & 14,4 & $8,5 \mathrm{a}$ & $4,33 \mathrm{a}$ & $19,9 \mathrm{a}$ & $1870 \mathrm{ab}$ \\
\hline Guandu & 17,8 & 15,8 & 10,3 a & $4,24 \mathrm{ab}$ & $18,7 \mathrm{a}$ & $1989 \mathrm{ab}$ \\
\hline Testemunha & 18,0 & 14,4 & 9,3 & 4,3 & 19,3 & 1888 \\
\hline R.C.S. & 16,4 & 13,8 & 10,0 & 4,0 & 19,5 & 1972 \\
\hline R.C.F. & 17,8 & 14,6 & 9,5 & 4,1 & 19,6 & 1990 \\
\hline R.C.S.+ R.C.F. & 17,2 & 14,1 & 9,5 & 4,2 & 19,1 & 1898 \\
\hline $\mathrm{CV}$ a $(\%)$ & 13,5 & 17,4 & 37,0 & 8,7 & 10,7 & 30,5 \\
\hline $\mathrm{CV}$ b $(\%)$ & 14,4 & 12,0 & 26,0 & 11,5 & 8,7 & 20,7 \\
\hline
\end{tabular}

Médias seguidas por letras minúsculas iguais na coluna não são diferentes entre si, pelo teste Tukey (P>0,05). *braquiária Brachiaria brizantha consorciada com milho; braquiária brizantha; capim mombaça (Panicum maximum; crotalária Crotalaria spectabilis; estilosantes Stylosanthes guianensis C.V. "a" coeficiente de variação na parcela, C.V. "b" na subparcela. 
Os autores não verificaram diferenças significativas na produtividade do feijoeiro tratado média de $1780 \mathrm{~kg} \mathrm{ha}^{-1}$, comparada à da testemunha $1687 \mathrm{~kg} \mathrm{ha}^{-1}$. Entretanto, Совиссі et al. (2005), aplicando regulador de crescimento (ácido índolbutírico $0,005 \%$, cinetina $0,009 \%$, e ácido giberélico $0,005 \%$ ), nas fases fisiológicas R5 e R7 do feijoeiro, relataram aumentos significativos na produtividade do feijoeiro - em torno de $30 \%$ na fase R5 (3816 kg ha-1), quando comparado à testemunha, independentemente do cultivo, de inverno ou verão. VIEIRA (2001) concluiu que, do uso de regulador de crescimento (ácido índolbutírico 0,005\%, cinetina 0,009\%, e ácido giberélico 0,005\%) no feijoeiro, resultaram aumentos significativos no número de vagens por planta, no número de grãos por planta e na massa seca de grãos por planta.

Não houve efeito positivo das culturas de cobertura no estande inicial e final, no número de vagem por planta, na massa de cem grãos do feijoeiro (Tabela 1). Silveira et al. (2005), avaliando a massa de cem grãos do feijoeiro cultivar Pérola, constataram menores valores na sucessão da braquiária consorciada $(24,0 \mathrm{~g})$ e da braquiária $(24,1 \mathrm{~g})$. Quanto ao estande inicial, isso pode ser atribuído ao fato de a semeadura ter sido realizada de forma manual.

Com as culturas de cobertura em sucessão ao feijoeiro foi proporcionado efeito positivo e significativo no número de grãos por vagem do feijoeiro. Com a cobertura de estilosantes obteve-se maior número de grãos por vagem - 4,3, sendo significativamente diferente do tratamento com braquiária solteira - 3,9 grãos por vagem, contradizendo ANDRADE et al. (1998); para estes autores a não-significância do número de grãos por vagem deve-se, provavelmente, a uma característica varietal.

Observou-se influência positiva e significativa da utilização de culturas de cobertura no sistema de sucessão no rendimento de grãos do feijoeiro (Tabela 1). Maiores valores de produtividade do feijoeiro foram na sucessão com milheto $\left(2485 \mathrm{~kg} \mathrm{ha}^{-1}\right)$, mombaça $\left(2120 \mathrm{~kg} \mathrm{ha}^{-1}\right)$, guandu (1989 $\left.\mathrm{kg} \mathrm{ha}^{-1}\right)$, braquiária consorciada com milho (1959 kg ha ${ }^{-1}$ ) e estilosantes $\left(1870 \mathrm{~kg} \mathrm{ha}{ }^{-1}\right)$. Toledo-Souza (2006) obteve produtividade de $3152 \mathrm{~kg} \mathrm{ha}^{-1}$ com a cultivar BRS Valente, na sucessão com milheto. Segundo Pitol (1999), dentre outras características de destaque, o milheto tem um sistema radicular com capacidade de desenvolvimento em maiores profundidades no perfil do solo, bem como uma elevada capacidade de extração de nutrientes. Os menores valores de produtividade do feijoeiro foram obtidos nas sucessões com braquiária $\left(1600 \mathrm{~kg} \mathrm{ha}^{-1}\right)$, crotalária $\left(1696 \mathrm{~kg} \mathrm{ha}^{-1}\right)$ e sorgo $\left(1777 \mathrm{~kg} \mathrm{ha}^{-1}\right)$.
O rendimento de grãos do feijoeiro não é positivamente influenciado pelo uso de regulador de crescimento tanto no tratamento de sementes quanto em aplicação foliar.

Em apenas um ano de sucessões, o rendimento do feijoeiro é positivamente influenciado por culturas antecessoras de cobertura, notadamente pela do milheto.

\section{REFERÊNCIAS}

ALLEONI, B.; BOSQUEIRO, M.; ROSSI, M. Efeito dos reguladores vegetais de Stimulate no desenvolvimento e produtividade do feijoeiro (Phaseolus vulgaris L.). Ciências Exatas e da Terra, Ciências Agrárias e Engenharias, v.6, p.2335, 2000.

ANDRADE, M.J.B.; DINIZ, A.R.; CARVALHO, J.G.; LIMA, S.F. Resposta da cultura do feijoeiro a aplicação foliar de molibdênio e as adubações nitrogenadas de plantio e cobertura. Ciência e Agrotecnologia, v.22, p.499-508, out.-dez. 1998.

CASTRO, P.R.C.; CATO, S.C.; VIEIRA, E.L. Biorreguladores e bioestimulantes em feijoeiro. In: FANCELLI, A.L.; DOURADO-NETO, D. (Ed.). Feijão irrigado: tecnologia \& produção. Piracicaba: ESALQ, 2005. p.54-62.

COBUCCI, T.; WRUCK, F.J.; SILVA, J.G. Resposta do feijoeiro (Phaseolus vulgaris L.) às aplicações de bioestimulante $\mathrm{e}$ complexos nutritivos. In: CONGRESSO NACIONAL DE PESQUISA DE FEIJÃO, 8., 2005, Goiânia. Anais... Santo Antônio de Goiás: Embrapa Arroz e Feijão, 2005. v.2, p.1078-1081.

PITOL, C. O milheto em sistemas de plantio direto. In: WORKSHOP INTERNACIONAL DE MILHETO, 1999, Planaltina, DF. Anais.... Planaltina: Embrapa Cerrados, 1999. p.69-71.

SILVA, M.G. Impacto de sistemas agrícolas na produtividade do feijoeiro irrigado e na qualidade biológica do solo. 2006. 116f. Tese (Doutorado em Agronomia: Produção Vegetal) Escola de Agronomia e Engenharia de Alimentos, Universidade Federal de Goiás, Goiânia.

SILVA, S.C.; SANTANA, N.M.P.; PELEGRINI, J.C. Informações meteorológicas para pesquisa e planejamento agrícola, referentes ao município de Santo Antônio de Goiás, GO, 2003. Santo Antônio de Goiás: Embrapa Arroz e Feijão, 2004. p.34. (Documentos, 163)

SILVEIRA, P.M.; BRAZ, A.J.B.P.; KLIEMANN, H.J.; ZIMMERMANN, F.J.P. Adubação nitrogenada no feijoeiro cultivado sob plantio direto em sucessão de culturas. Pesquisa Agropecuária Brasileira, v.40, p.377-381, 2005.

TOLEDO-SOUZA, E.D. de. Influência de sistemas de cultivo e de sucessões de culturas em patógenos de solo do feijoeirocomum (Phaseolus vulgaris L.). 2006. 100f. Tese (Doutorado) Departamento de Biologia, Universidade de Brasília, Brasília. 
VIEIRA, E.L. Ação de bioestimulante na germinação de sementes, vigor de plântulas, crescimento radicular e produtividade de soja (Glicine max), feijoeiro (Phaseolus vulgaris L.) e arroz (Oryza sativa L.). 2001. 122f. Tese (Doutorado) - Escola Superior de Agricultura Luiz de Queiroz, Universidade de São Paulo, Piracicaba.

WUTKE, E.B.; FANCELLI, E.B.; PEREIRA, J.C.V.N.A.; AMBROSANO, G.M.B. Rendimento do feijoeiro irrigado em rotação com culturas graníferas e adubos verdes. Bragantia, v.57, p.325-338, 1998. 